\title{
Opintokerholiikkeen juuret ovat Amerikassa
}

"Näin ollen on johdonmukaista ... antaa kunnia opintokerhometodin luomisesta yksin Oscar Olssonille", kirjoitti Timo Toiviainen Aikuiskasvatus-lehden viime numerossa $(4 / 2001,382)$. Englantilainen Peter Jarvis, jonka teosta An International Dictionary of Adult and Continuing Education (1990) Toiviainen käyttää lähteenään, pitää Olssonia Ruotsin opintokerholiikkeen perustajana ${ }^{1}$. Suomeen 1900-luvun alussa rantautuneen ryhmämuotoisen opintotoiminnan juuret ovat kuitenkin vankasti amerikkalaisessa Chautauqua-liikkeessä.

$\mathrm{M}$ aassamme 1800-luvun loppupuolella virinneet pyrkimykset kansan sivistystason kohottamiseen saivat herätteitä eurooppalaisista aatevirtauksista. Nuorella sivistyneistöllä oli yhteyksiä Keski-Eurooppaan ja Pohjoismaihin ja heidän mukanaan vapaa kansansivistystyö sai herätteitä ja vaikutteita ulkomailta. Autonomian ajan lopulla pohjoismaiset ja keskieurooppalaiset yhteydet rikastivat maamme kansansivistystyötä, mutta ideoita saatiin myös Yhdysvalloista (Karjalainen 1970, 21). Yksi maamme vapaan sivistystyön työmuoto, opintokerho, on saanut herätteitä amerikkalaisesta Chautauqua-liikkeestä. Liike sai alkunsa vuonna 1874 New Yorkin osavaltiossa sijaitsevan Chautauqua-järven rannalla pidetystä pyhäkoulunopettajien kesäisestä lomakurssista. Lomakurssia päätettiin ensimmäisen kerran jälkeen jatkaa vuosittain ja autiojärven rannalle kasvoi vähitellen suuri kesäinen kaupunki, johon kerääntyi heinä-elokuussa kymmeniä tuhansia ihmisiä opiskelemaan. Talvella seutu oli miltei autio.

Kesäohjelmaan kuului luentoja ja lyhyitä kursseja eri tieteen aloilta. Toimintaan saatiin mukaan myös yliopistot, järjestöt ja kirkko. Kesätoimintaan osallistuneet halusivat jatkaa opiskelua myös talvella ja niin sai alkunsa kirjallisuus- ja tiedepiiri vuonna 1879. Aluksi julkaistiin luetteloita sopivista kirjoista, mutta jo samana vuonna alettiin antaa kirjallista ohjausta yksinopiskelijoille. Opintotoiminta tapahtui joko itseopiskeluna tai siihen voitiin yhdistää opintopiirityöskentely.

\section{Raittiusliike, Chautauqua ja Ruotsi}

Juonna 1851 Amerikassa syntynyt raittiusliike International Order of Good Templars (IOGT) käynnisti opintotoiminnan 1880-luvulla ja otti mallia Chautauqua-liikkeen opintojärjestelmästä. IOGT-liike levisi vähitellen Amerikasta Eurooppaan. Ruotsiin liike tuli vuonna 1879. Vuonna 1891 IOGT:n maailmankonferenssissa oli esillä järjestön koulutusjärjestelmän luominen kolmivuotisten itseopiskeluun perustuvien kurssien pohjalle. Ruotsissa asetettiin komitea laatimaan omaa valtakunnallista suunnitelmaa. Ruotsin IOGT:n johtaja Edward Wawrinsky teki tutustumismatkan Amerikkaan ja vieraili matkallaan myös Chautauquassa. Hänen saamansa vaikutelmat näkyivät komitean valmistamassa suunnitelmassa, joka valmistui vuonna 1895. Suunnitelmassa esitettiin järjestettäväksi kahdenlaisia kursseja: raittiuskursseja ja yleiskursseja. Kurssitoiminta käynnistyi, mutta opintoihin osallistuminen oli aluksi varsin vähäistä. Kolmen ensimmäisen toimintavuoden aikana aloittaneista kursseista miltei puolet jäi kesken ja vain jotkut osallistujista jatkoivat toiselle työkaudelle.

\äänne Ruotsin opintotoiminnassa tapahtui vuonna 1902, kun filosofian kandidaatti Oscar Olssonin ehdotus tulevaksi opintotoiminnaksi ilmestyi Reformatorn-lehdessä. Hänen mukaansa opettajajohtoiset pitkät kurssit, luennot ja kirjallisuuden levittäminen eivät olleet herättäneet kansan lukuhaluja. Lukurenkaiden pe- 
rustaminen vuonna 1900 oli osoittautunut kurssitoimintaa paremmaksi vaihtoehdoksi. Hän ehdottikin opintokurssien, lukurenkaiden ja kirjastojen hyvien puolien yhdistämistä uudenlaiseksi opintopiirijärjestelmäksi (Totro 1979, 34-39).

Opintopiirin jäsenmääräksi Olsson suositteli 530 jäsentä. Jos jäsenmäärä ylitti 40, tuli se jakaa kahtia. Piiriin tuli hankkia yhtä monta opiskeltavaa kirjaa, kuin siinä oli jäseniä. Opiskeltaviksi aiheiksi Olsson ehdotti uskontofilosofiaa, valtio- ja yhteiskuntaoppia historiaa, kaunokirjallisuutta ja raittiustietoutta (Nerman 1952, 52). Kirjat piiriin valittaisiin työkauden alussa ja ne kiertäisivät piirin jäsenillä kahden viikon välein. Tutkintoja ei ollut ja opintopiiri saattoi toimia ilman asiantuntijaohjaajaa, kunhan sillä olisi aloitekykyinen johtaja. Kirjat oli määrä jättää työkauden jälkeen loosin kirjastoon käytettäväksi tarpeen mukaan. Olssonin ehdotus opintopiireiksi otettiin IOGT:n opinto-ohjelmaan jo toiminnassa olevien opintokurssien ja lukurenkaiden ohella ja siitä kehittyi vähitellen vuodesta 1904 lähtien järjestön pääopiskelumuoto.

Ruotsin IOGT:n lukurengas- ja opintopiirijärjestelmän esikuvina olivat amerikkalainen Chautauqua-malli ja amerikkalaisen IOGT-järjestön Chautauqua-mallista kehittämä opintojärjestelmä. Olssonin kehittämä opintopiiri oli kuitenkin joustavampi opiskeluaineiston valinnan osalta eikä opintopiirissä järjestetty tutkintoja. Opintopiiristä puuttui kaikki koulumaisuus ja jäykkä yhdistystoiminta. Se sai itse päättää, mitä aineita opiskellaan, millaisia opintomenetelmiä käytetään ja kenet valitaan opintojen ohjaajaksi. Opintokokouksissa viihtyvyystavoitteet olivat yhtä tärkeitä kuin opintotavoitteetkin.

\section{Chautauqua ja Suomi}

$\mathrm{M}$ eillä Suomessa 1800-luvun lopulla syntyi eri puolilla maata aikuisten omaehtoista opintotoimintaa. Kiinteämmät muodot opintotoiminta sai kuitenkin vasta sitten, kun ulkomaiset opintoliikkeet tulivat meillä tutuiksi ja kun kansalaisjärjestöt ryhtyivät edistämään opintotoimintaa.

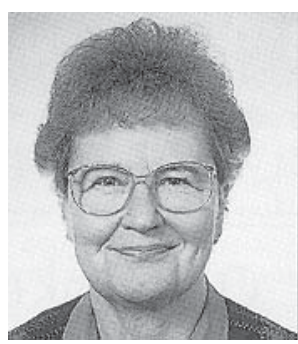

Oili Parjo

A merikkalaista Chautauqua-liikettä esitteli ensi kerran professori I. A. Heikel ${ }^{2}$ jo vuonna 1898 eräässä ruotsinkielisessä kalenterissa. Seuraavan kerran Chautauqua-liike oli esillä Kansallismielisen Nuorison Liiton kesäkokouksessa 1909. Tällöin tohtori O.A. Hainari ${ }^{3}$ esitteli liikettä kokousedustajille. Kansallismielisen Nuorison Liitto ottikin opintojärjestelmänsä mallin Chautauqualiikkeestä. Jo vuonna 1902 Väinö Voionmaa ${ }^{4}$ osallistuttuaan Tukholmassa pidettyyn pohjoismaiseen raittiuskokoukseen teki Raittiuden Ystäville esityksen raittiustutkintolukujen järjestämisestä. Opiskelun suunnittelussa viitattiin amerikkalaiseen Chautauqua-liikkeeseen, englantilaiseen raittiusliikkeen, jonka esikuvana oli ollut amerikkalainen IOGT-liike ja Ruotsin goodtemplarien opinto- ja tutkintojärjestelmiin (Totro 1979, 50-51, 67). Suomen Nuorison Liiton kesäkokouksessa vuonna 1908 Väinö Voionmaa esitteli opintopiiritoiminnan mahdollisuuksia nuorisoseuratyössä käyttäen mallina Ruotsin goodtemplarien opintojärjestelmää.

Quomen Kristilliseen Työväen Liittoon ruotsaNaisen Olssonin opintopiirin mallin toi sosiaalineuvos Vihtori Karpio ${ }^{5}$ vuonna 1907 ja se levisi lukurengastoimintana eri puolille maata paikallisyhdistyksiin (Totro 1979, 73-74, Peltoniemi 1963, 29). Järjestöjen organisoima opintotoiminta ei aluksi saavuttanut niin laajoja piirejä, kuin oli toivottu. Opiskeltavien aineiden kirjo oli suuri, vaikeusaste vaihteleva, eikä opiskelussa ollut ohjausta. Monet opintokerhot eivät päässeet opiskelussa tutkintoihin asti ja opintojen keskeyttäminen oli tavallista.

Uusi vaihe opintotoiminnassa koettiin, kun vuonna 1907 perustetun Kotikasvatusyhdistyksen sihteeri, opettaja Vilho Reima ${ }^{6}$ esitteli ame- 
rikkalaiseen Chautauqua-malliin perustuvan opintojärjestelmänsä. Hän yksinkertaisti mallia siten, että opiskeltavaksi otettiin vain yksi aihe ja yksi kirja ja opiskelun päätteeksi suoritettiin opiskellusta aiheesta tutkinto. Kun soveliaita opintokirjoja ei ollut, Kotikasvatusyhdistys toimitti opiskeltavaksi vuosittain oman opintokirjan. Muut järjestöt vierastivat aluksi järjestelmää

\section{Opintokerho pähkinänkuoressa}

$\mathrm{O}$ pintokerho on muutaman aikuisen muodostama opinnollinen ryhmä, joka opiskelee omatoimisesti jotain valitsemaansa aihetta. Ryhmä valitsee keskuudestaan ohjaajan, kierrättää vetovastuuta tai voi kutsua ryhmän kokoontumisiin ulkopuolisen asiantuntijan.

Valtio alkoi tukea opintokerho-opiskelua pienin opintokerhokohtaisin summin jo vuonna 1921, jolloin myös tuli tarpeelliseksi määritellä opintokerho selkeästi: sen kokoontumiskertojen vähimmäiskesto ja -määrä, ryhmän vähimmäiskoko ja opintokerhon opinnolliset tavoitteet.

Opintokerhotyön uranuurtajia on Suomessa ollut oheisessa kirjoituksessa kerrottujen kotikasvatusyhdistysten lisäksi Työväen Sivistysliitto (perustettiin 1919 Voionmaan aloitteesta), Valistusjärjestöjen opintotoimikunta $^{1}$ (perustettiin Kansanvalistusseuran yhteyteen 1922) ja sen työn jatkaja Opintotoiminnan Keskusliitto (vuodesta 1943, vanhin sitoutumaton opintokeskus) sekä Maaseudun Sivistysliitto (vuodesta 1952). Opintokeskusten määrä on ollut 1980-luvun lopusta lähtien valtion rajaamana vakio: valtakunnallisia opintokeskuksia on nykyisin 11, joista seitsemällä on poliittisaatteellinen tausta.

Opintokerho on ollut vuosikymmenten ajan kansalaisjärjestöjen perustoimintamuotona paikallis- ja ruohonjuuritasolla. Sen avulla on edistetty kansalaisjärjestöjen tavoitteita palvelevia tietoja, taitoja ja asioidenhallintaa sekä toiminnan piirissä olevien tarvetta kansalaisaktiivisuuteen opinnollisin ja itseä kehittävin keinoin. Ylivoimaisesti suosituimpia ovat olleet yhteiskunnalliset aiheet.

Voimakkaimmillaan opintokerho on ollut 1970- ja 80-luvulla, jolloin kerhoja oli vuosittain 20000 molemmin puolin. Korkeimmillaan luku kävi vuosina 1982-83, noin 26000 kerhossa. Korkeiden lukujen takaa paljastui kuitenkin kerhopaperitehtailua ja väärinkäytöksiä, minkä seurauksena tämän hienon, demokraattisen opintomuodon maine sai ankaran kolauksen ja osittain sen seurauksena opintokeskukset suuntautuivat toiminnassaan voimakkaammin lyhytkursseihin. Seuranneeseen opintokerhon hiljaiseen kauteen on vielä tärkeämpi syy: elämän voimakas privatisoituminen ja ihmisten lisääntynyt passiivisuus tehdä kansalaisjärjestöjen perustyötä. Toisaalta toinen likeinen opiskelumuoto, kansalaisopistokurssit, kilpailevat osin samojen ihmisten aktiivisuudesta. Opintokerho onkin ollut kansalaisopistopedagogiikan esikuvana. Molemmissa ihmisten lähellä toimivissa ryhmäopintomuodoissa yhdistyvät niiden tärkeimmät ja arvokkaimmat elementit: asian harrastaminen, opinnollisuus ja sosiaalisuus.

Suomessa opintokerho ei ole saanut saman mittaluokan suosiota kuin naapurissa Ruotsissa, jota Olof Palme luonnehti aikoinaan opintokerhoyhteiskunnaksi (studiecirkelsamhället), mutta mistä vuorostaan puuttuvat meidän vahvat kansalais- ja työväenopistomme. Nämä kaksi pienryhmäopiskelun muotoa yhteenlaskettuna lienemme varsin rinnasteisia yhteiskuntia.

Tarkemmat tiedot opintokeskuksista yhteystietoineen saa netistä sivulta www.vsy.fi sekä niiden tarjoamista koulutuspalveluista kunkin opintokeskuksen omilta kotisivuilta. Nykyisin valtio tukee opintokerhoja vuosittain noin 8,8 miljoonalla markalla.

\section{ANNELI KAJANTO}

1 Erkki Karjalainen (1970) Suomen vapaan kansansivistystyön vaiheet, sivu 173. 
pitäen sitä liian helppona. Opiskelijat voisivat yhden vähäisen kirjan luettuaan luulla osaavansa kaikki aiheesta. Arvostelusta huolimatta jotkut järjestöt ottivat ohjelmaansa Kotikasvatusyhdistyksen opintokirjoja ja sovelsivat opintotoimintaan Kotikasvatusyhdistyksen opintotojärjestelmää (Karjalainen 1970, 66, Parjo 2001, 140).

Quomalaisen opintokerhotoiminnan juuret on Nöydettävissä Amerikassa alkunsa saaneista Chautauqua-liikkeestä ja IOGT-liikkeestä osittain suoraan, osittain Englannin ja Ruotsin kautta tänne rantautuneena ja matkalla uusia piirteitä saaneena. Järjestömuotoisen sivistystyön, opintokerhotoiminnan ulkomaiset esikuvat ovat kiistattomia. Ne eivät kuitenkaan sellaisenaan soveltuneet oloihimme, vaan vaativat runsaasti soveltamista. Jos Oscar Olssonia pidetään yhtenä ruotsalaisen opintokerhon mallin luojana, voidaan meillä Suomessa kehittyneen ja 1920-luvulla yleistyneen opintokerhon mallin luojana pitää Vilho Reimaa.

\section{Lähteet}

ANDERSSON, Bo (1980) Folkbildning i perspektiv. Studieförbunden 1870-2000. Organisering, etablering och profilering. Stockholm

NERMAN, Ture (1952) Studiecirkeln. Stockholm

KARJALAINEN, Erkki (1970) Suomen vapaan kansansivistystyön vaiheet. Tapiola

PARJO, Oili (2001) Kotikasvatus koko kansan asiaksi. Lisensiaattitutkimus, Helsingin yliopiston kasvatustieteen laitos. Tarkistettu 16.1.2002.

PELTONIEMI, U. (1963) Neljä vuosikymmentä opintokerhotyötä. Helsinki

TOTRO, Timo (1979) Uskontokasvatus kansalais- ja kotiopintoliikkeessä. Helsinki

\section{Viitteet henkilöihin}

1 "Olsson, Oscar (1877-1950) Founder of the Swedish study circle movement in 1902 at the Lund branch of the International Order of Good Templers. He was a leader in the Swedish temperary movement, and involved in many other activities in Sweden. He wrote material for the study circles and believed that books and libraries were important in the education of adults. He was also an international figure in other movements." (Jarvis 1990, 250).

Jos tuo ehdotus hyväksytään opintokerhometodin kiintopisteeksi Ruotsissa, opintokerhotyön voidaan katsoa täyttävän tänä vuonna naapurimaassamme Ruotsissa sata vuotta.
Ivar August Heikel (1861-1952) oli filosofi ja 2 yliopistomies. Hän toimi liki neljänkymmen vuoden ajan Helsingin yliopiston kreikan kirjallisuuden professorina, pari eri kautta yliopiston rehtorina. Hänen tuotantonsa oli huomattavan laaja käsittäen niin tieteellisiä kuin yleistajuisiakin julkaisuja, ennen muuta antiikin aihemaailmasta. Ivar Heikel toimitti lukuisia luku-, oppi- ja sanakirjoja, mm. latinalaissuomalaisen sanakirjan, kreikkalais-ruotsalaisen sanakirjan Uuteen testamenttiin ja Apostolien tekoihin sekä kolme muistelmateosta.

3 Tohmajärveläinen filosofian tohtori Oskar Haina3 ri, alkuaan Forsström, oli historiantutkija, koulumies (mm. Sortavalan ja Jyväskylän lyseoissa) sekä suomalaisen puolueen kansanedustaja ensimmäisissä eduskunnissa. Hän harrasti Raja-Karjalan olojen parantamista ja kirjoitti useita teoksia Inkeristä ja Raja-Karjalasta.

4 Väinö Voionmaa (1869-1947) oli historiantutkija, kansansivistysmies ja sosiaalidemokraattinen poliitikko. Voionmaa oli eduskunnan jäsen liki 30 vuoden ajan aina kuolemaansa saakka, useampaan otteeseen ministerinä, mm. ulkoministerinä 192627. Hän kuului Suomen rauhanvaltuuskuntaan Tartossa 1920 sekä Moskovassa 1940 ja 1946. Väinö Voionmaa oli Kansanvalistusseuran sihteeri vuosina 1907-12, Työväen Sivistysliiton pitkäaikainen puheenjohtaja 1919-47 ja mm. Työväen akatemian esimies. Voionmaa julkaisi lukuisia teoksia, ennen muuta Suomen taloushistoriasta, Suomen yleisestä historiasta sekä talous- ja yhteiskuntakysymyksistä. Väinö Voionmaan isä Olavi Wallin oli 1800-luvulla huomattava kansakoulumies ja kansakoulupedagogiikan kehittelijä.

5 Viipurilaissyntyinen Vihtori Karpio oli aktiivi$\mathcal{~ n e n , ~ e l i n i k a ̈ i n e n ~ r a i t t i u s m i e s . ~}$

6 Vilho Reima (vuoteen 1906 Reiman, 1867-1948) O kävi Amerikassa kaksi kertaa. Molemmista näistä matkoistaan hän kirjoitti Kansanvalistusseuran kalentereissa ("Ensimmäiset suomalaiset raatajat Minnesotan mailla Amerikassa, 1907, sekä "Suomalaiset maanviljelijöinä Minnesotan metsissä", 1911). Kansakoulunopettaja, myöhemmin kouluneuvos Vilho Reima oli tunnettu kasvatusmies, raittiusyhdistys Koiton puheenjohtaja vuosisadan taitteen molemmin puolin, Kotikasvatusyhdistyksen perustajajäsen ja pitkäaikainen toiminnanjohtaja sekä Koti-lehden toimittaja vuodet 1910-40. Reima sai opintokerhoidean Hainarin kirjoituksista. Amerikasta hän sen sijaan toi toisen tärkeän innovaation, äitienpäivän, jonka vietto vakiintui Suomeen 1920-luvulla. Reima oli suomalaisen puolueen kansanedustaja ensimmäisessä eduskunnassa. Hänestä on Väinö Seppä kirjoittanut kirjan Rikas elämä. Tuore tutkimus Vilho Reimasta ja hänen kasvatustyöstään on Oili Parjon 16.1.2002 tarkistettu lisensiaattitutkimus, ks. lähteet.

$\mathrm{O}$ ili Parjon lisensiaattityön lausunnonantaja Timo Toiviainen arvioi ja esittelee Parjon tutkimusta lehden verkkosivuilla www.kvs.fi > Aikuiskasvatusjulkaisut $>$ Aikuiskasvatus $>$ Tärppejä nettilukijalle. Otsikkona on "Uusinta uutta tutkimuksesta". 